\title{
El misterio de la voz búlgara: reflexiones sobre la alineación laboral 1
}

\author{
Manuel Reguillo Cruz * \\ Sin trabajo toda vida se marchita; \\ pero cuando al trabajo le falta alma, \\ un espíritu que lo anime, \\ la vida se asfixia y muere. \\ Albert Camus, Quotes
}

Durante los últimos años, con la creciente sensibilidad al posible conflicto entre los objetivos de pleno empleo y estabilidad de precios, se ha tendido a definir el empleo como el nivel mínimo que puede alcanzar el desempleo con una expansión de la demanda global que no provoque un alza inaceptable del nivel de precios. Esta definición indica explícitamente que el objetivo de empleo depende de la posibilidad de conciliación de la reducción del desempleo, con el alza consiguiente (si es que se produce) del nivel de precios.

William Beveridge, El Informe de 1942

\section{Fuentes fundamentales}

Revisando el estado del arte en materia de sistemas abiertos de trabajo, he encontrado que muchas empresas que habían optado por esta alternativa, han tenido que volver su vista atrás. Anthony Giddens (2000) ha declarado que el consenso del bienestar al que se llegó en la Unión Europea a finales de los 90 suponía otra vuelta de tuerca a los sistemas de trabajo participativos que habían sufrido un súbito declive a partir del boom de las globalizaciones, particularmente las que se refieren a la tecnología y al empleo $^{2}$. Con el ir y venir continuo de personas en busca de empleo, gente que deja su país con el deseo de encontrar el trabajo que no tienen en el propio, y con las empresas de alta tecnología y electrónicas exportando su know-how a, prácticamente, cualquier país que esté dispuesto a aceptar su dominación técnica, la vuelta de tuerca de Giddens se convierte en un referente a su famosa Tercera Vía.

Cuando decidí escribir este ensayo recurrí a mis apuntes y notas de mis cursos en la UCLA (University of California in los Angeles). Yo había sido estudiante y alumno del Dr. Louis Davis ${ }^{3}$ en los ya lejanos años 80 Algo que recordé al comenzar mi ensayo y que leí en mis apuntes, como para comprobar que la memoria no me fallaba, fue la insistencia del Dr. Davis en 
que para comprender los sistemas abiertos de trabajo ${ }^{4}$ necesitábamos acudir a muchas fuentes, pero que eran fundamentales Max Weber (1978), Frederick Taylor (1993), Talcott Parsons (1985) y Ludwig von Bertalanffy (1972).

Parsons (1985) ha escrito abundantemente sobre sistemas sociales, siendo su contribución más importante la incorporación que hace de las distintas correlaciones de aquéllos con el sistema de acción, el ambiente en que se mueve el sistema social, la comunidad societal y los sistemas culturales y políticos.

Por su parte, Bertalanffy (1956; 1972), es responsable de una de las primeras formulaciones de la teoría general de los sistemas. Cuando habla de los sistemas vivos señala que la búsqueda de un objetivo no es privativo de ellos. Estableció la diferencia entre un sistema aislado (P. Ej. reacciones químicas) y otro abierto (es decir, con fuentes y desagües). En un sistema aislado su estado final depende de las condiciones iniciales, mientras que en uno abierto, el estado final del sistema es independiente de las condiciones iniciales. Parecería ser que en un sistema abierto se persigue un propósito: el de mantenerse en estado estacionario. Así pues, Bertalanffy enfatiza por primera vez que los organismos vivos son sistemas abiertos. Este concepto sería de fundamental importancia para el rediseño de organizaciones.

En la obra de Max Weber algunos sociólogos han pretendido ver los problemas de significado planteados por la aparente relación entre la personalidad individual y el sistema social con su ambiente físico. Todas las relaciones con éste se dan a través del organismo, que es el vínculo primario de acción con el mundo físico. Los sistemas sociales, pues, para seguir a Weber, no tienen contacto directo con la "realidad última" (Parsons, 1985: 711); este enfoque debería ayudar a la exploración de los sistemas sociales. Y finalmente, traigamos a colación a Frederick Taylor (1993), un ingeniero estadounidense asociado a dos grandes problemas de las organizaciones modernas: el imperativo tecnológico, privativo de toda organización, y el uso del concepto de burocracia de Weber para conformar el binomio que forma parte aún del sistema dominante. Esto es, la burocracia tecnocrática.

Tenemos aquí a cuatro grandes teóricos de disciplinas variadas: sociología, ingeniería industrial y biología. Trataremos de incorporar su pensamiento en el desarrollo de este ensayo cuyo objetivo es comprender la constitución de los sistemas sociales en la actualidad y cómo intentaron enfrentar la alienación laboral.

\footnotetext{
* Manuel Reguillo Cruz es ingeniero químico (Universidad de Guadalajara), Maestro en Ciencias (Universidad de Monterrey) y Candidato al Doctorado en Estudios Científicos Sociales del Instituto
} 
Tecnológico de Estudios Superiores de Occidente (ITESO). Ha sido gerente corporativo de Desarrollo Organizacional para empresas como Motorola, Inc. y General Electric. Ha sido consultor "in-House" para Motorola de Puerto Rico y consultor de procesos de cambio para Motorola International. Actualmente es consultor independiente en procesos de transformación y multiculturalidad. Su especialidad son los sistemas de trabajo.

\section{El binomio burocracia-tecnocrática}

Max Weber escribió en 1904 sus grandes postulados sobre la organización eficiente y perfecta. Le llamó la jaula de hierro a la que hay que adaptarse. Para él los funcionarios están organizados como una jerarquía de mandos. Añade que "aquéllos son remunerados mediante un sueldo y no reciben gratificaciones por servicios" (1978: 87). La autoridad de los funcionarios proviene de su cargo; su nombramiento es determinado por méritos probados (no por recomendaciones). Las decisiones deben ser tomadas de acuerdo a "reglas estrictas establecidas de antemano" (1978: 90); las burocracias actúan mediante la aptitud técnica y mantienen un registro de sus actuaciones.

Weber afirmaba que este tipo de organización es el más eficiente y confiaba que se propagara por todo el mundo moderno. Sus críticos y detractores pronto habrían de probar que estaba equivocado. Un país, cuya quintaesencia era el burocratismo, la China Imperial, estaba agobiada por el cohecho, la corrupción y el favoritismo. También los teóricos de Weber que afirmaron que el mundo moderno sería burocrático, tendrían su derrota en el avance del capitalismo que tuvo que descentralizar las decisiones que se tomaban dentro de la organización.

Weber también escribió sobre los tipos de dominación que existen, ya que la autoridad es un fenómeno mundial. $\mathrm{Y}$ así, hay líderes carismáticos, tradicionales y jerárquicos (impuestos por la organización misma). El poder que la organización le otorga a este último tipo de dominación constituye un campo de estudio por sí mismo porque implica la naturaleza de la legitimidad del poder que obtienen los líderes y de dónde proviene; sobre esto se han escrito miríadas de ensayos, artículos y libros. La sociología subraya la importancia que este tipo de poder tiene sobre sus subordinados. También es interesante notar que no todas las estructuras organizacionales favorecen un liderazgo de esta naturaleza, es decir, de un poder absoluto. Particularmente en las estructuras gubernamentales esto es muy evidente. La legitimidad de un líder bajo el tipo de dominación que señala Weber debería verse bajo la luz de los medios de comunicación, sobre todo en la situación actual.

Sin embargo, durante la primera mitad del siglo veinte y buena parte de la 
segunda, el concepto burocrático se infiltró, proliferó y dominó las formas de administración de las organizaciones occidentales modernas. Podríamos afirmar que hemos vivido bajo el influjo de Weber por más de cien años. Pero burocracia es sólo una parte de la fórmula. Otra figura señera en materia de organizaciones habría de marcar al siglo veinte con su impronta: el complemento que hacía falta.

\section{El imperativo tecnológico}

Ya hemos mencionado más arriba que en 1911 un ingeniero mecánico con un marcado interés en los rendimientos de las máquinas de producción publicaba un libro que sería el más famoso y más influyente en la primera mitad del siglo veinte en cuanto a productividad, rendimientos, comportamiento económico de la empresa y la teoría de mercados de Keynes (ya que su protector Henry Ford había aceptado los lineamientos del gran economista en materia del encuentro para los acuerdos que se daría en las postrimerías de la Segunda Guerra Mundial entre patrón y trabajador).

El libro en cuestión era The Principles of Scientific Management (1993), y su autor Frederick Winslow Taylor; en él afirmaba que "el principal objeto de la administración debería ser asegurar la máxima prosperidad del empleador, aunado a una máxima prosperidad para cada empleado" (1993: 101). Sin duda, este texto catapultó a Taylor como alguien que cuestionó el orden establecido en materia de productividad y de la división del trabajo. El apoyo que le dio el magnate Henry Ford llevó a que en las líneas de ensamblado automotrices se pudieran intercambiar las partes del automóvil, pues hasta entonces cada una de ellas (pistón, engranes, etc.) tenía que ser ensamblada individualmente. También dio lugar a que la línea movible de producción redujera el movimiento de los trabajadores, simplificando el trabajo y resultando en el intercambio de la fuerza laboral. La asociación de Taylor con Ford dio origen a la edad dorada del capitalismo. Ésta se caracterizaba por la existencia de empresas de producción a gran escala con las ideas de Taylor en las naves de producción y con una alta división del trabajo, y con créditos al consumo que crecían día a día. Esta etapa de prosperidad duró desde 1940 hasta la década de 1970.

Las ideas de Taylor se aplicaron por primera vez en la planta automotriz de Ford en Detroit en 1913, y de ahí pasaron al resto de las industrias. Se trata, pues, de la racionalización de los procesos productivos al diferenciar los procesos de creación y ejecución, dando un mayor control sobre la producción a los gestores de la misma. Obviamente, los aspectos mentales quedaban separados de los procesos de producción y de tareas manuales.

Los movimientos sindicalistas se opusieron al principio al taylorismo, pero acabaron por ceder a cambio de mayores ganancias derivadas de los 
incrementos de la productividad y de los rendimientos por la intensificación debida a la racionalización del trabajo.

Henry Ford tuvo la sagacidad y la visión para anticipar que el trabajador no sólo era una conveniencia o un factor de producción, sino que también era un consumidor final, y por tanto, al considerarlo así, las ganancias de productividad y el reparto del mayor valor añadido, mediante incrementos al salario, crearon una mayor demanda del consumo, y así hacer frente al aumento en los volúmenes de producción dados los progresos de tipo técnico que se estaban dando gracias al taylorismo.

Los treinta años a los que hacemos referencia y que marcaron los años dorados del capitalismo americano se caracterizaron por ser una época de pleno empleo, alta inversión de capital y el uso pleno de la capacidad productiva. Baudrillard le ha llamado a tal época "la sociedad de consumo" (2003:45). Según Baudrillard, el aumento del consumo se da cuando se pone en juego un círculo perverso que comienza con un incremento en la capacidad instalada para generar, a su vez, un exceso de capacidad productiva, cayendo en la certeza de que existe tal cosa como productividad ilimitada. De esta manera se dispone del producto con controles estrechos de los mecanismos de producción y, de esta forma, el consumo, su demanda y su incremento quedan asegurados. El ciclo vuelve a empezar.

La época en cuestión fue como un estado de bienestar en el sentido que ha descrito Giddens (2000). Dicho estado de bienestar era demasiado caro para sostenerse por mucho tiempo. A finales de la década de 1960 la crítica al fordismo generada por la tensión de unas relaciones sociales cada vez más alienadas, hizo que los antiguos acuerdos sobre el estado de bienestar se cuestionaran bajo la luz de nuevas tecnologías, descentralización de decisiones, sistemas de producción esbeltos como el de Toyota, y por el monetarismo como corriente económica que lideraba a los gobiernos en las fuerzas del mercado y que ganaba cada vez más hegemonía. El estado de bienestar se resquebrajaba, era demasiado frágil: el fordismo tenía el germen de la destrucción en sí mismo. Se acercaba el nacimiento de una nueva belleza terrible (Yeats, 1999).

\section{Modos de producción y culturas de trabajo}

Se pueden distinguir claramente tres grandes etapas en los modos de producción: 1) granja familiar y taller artesanal, 2) producción en masa, y 3) producción esbelta. La naturaleza del trabajo y de las organizaciones ha cambiado. Son la resultante de la reflexión de tendencias mayores como educación, tecnologías de información y comunicación.

Mucho de la historia en este planeta vio el trabajo definido en pequeñas organizaciones. Eran las granjas familiares y los talleres artesanales: 
prácticamente lo mismo (unas hacían el trabajo fuera y los otros dentro de un recinto). Eran un grupo pequeño de individuos que tenían lazos de intimidad, interdependientes y psicológicamente cercanos, eran una familia. Compartían roles y responsabilidades. No estaban constreñidos a tareas simples y sencillas. No hacían un producto a menos que recibieran un pedido de un cliente. No se podían permitir almacenar muebles o instrumentos. Eran "diseños a la medida". Cada unidad de producto, cada pieza de mueblería, instrumento musical o vagón eran únicos, y tenía sus partes ensambladas individualmente. Este toque artesanal requería destreza y paciencia. Era un trabajo muy demandante de tiempo: este era el sistema estándar de producción antes del automóvil. Era un sistema más efectivo humanamente que como un sistema de producción. Tal sistema se extinguiría al arribo de la Primera Revolución Industrial.

Además de crear una nueva burguesía de empresarios, dueños de fábricas, la Revolución Industrial también originó una nueva clase trabajadora. Esta incluía a todos los hombres, las mujeres y los niños trabajando en las fábricas textiles, alfarerías y minas. Muy a menudo los artesanos habilidosos, que antes hacian sus bienes a mano y con gusto creador, ahora eran reducidos a obreros rutinarios dentro de una producción en masa a medida que las máquinas mejoraban su eficiencia. En general los salarios eran bajos, las horas largas y las condiciones físicas y psicosociales bastante precarias.

La cuota de inmigración de Estados Unidos en 1920 pasó a ser 20\% superior a los 35 años anteriores (Lacqueur, 1989). Eran principalmente rusos, eslavos y polacos. Éstos, sumados a los cientos de miles de italianos e irlandeses que ya se habían establecido, conformaron una fuerza de trabajo formidable cuya energía fue aprovechada por la industria, particularmente la naciente industria automotriz que ya ha sido descrita más arriba.

El taylorismo produjo una escisión: los aspectos mentales quedaron separados por completo de las tareas manuales. Esto constituyó una ruptura total con los métodos de producción del pasado, cuando la producción se organizaba en función del tipo de artesanía y los artesanos creaban, organizaban y completaban las tareas manuales. En las líneas de ensamblado los trabajadores estaban separados del proceso de mejora. Éste era un campo bajo el dominio de los especialistas, ingenieros industriales, que estudiaban y definían los métodos de trabajo. Se desarrolló una jerarquía de ingenieros y sus propias organizaciones. Después le siguieron Contabilidad, Mercadeo, Diseño y otras, copiando el modelo. Cada uno desarrollaba su propio lenguaje, cada vez más complejo y más separado del de los demás. Se construyeron muros y barreras (silos). Estos no sólo eran 
entre departamentos sino entre modos de pensamiento, comunicación y comprensión.

\section{Fronteras permeables}

Mencionábamos más arriba que el sistema dominante de organización ha sido el de la burocracia tecnocrática. El binomio Weber/Taylor sigue vigente en gran parte del mundo del trabajo occidental. Aunque el clima de la sociedad es más receptivo, en la mayoría de los países occidentales las bases de apoyo al cambio siguen limitadas por la permanencia en el poder de la tecnocracia y la burocracia.

Dicho cambio comenzó con la crisis generada en las postrimerías de la Segunda Guerra Mundial (Womack, 1990) en las minas de carbón de Inglaterra, y que además eran la principal fuente de poder y energía. Este país era el primer productor de carbón mineral del mundo. Después de la guerra las minas pasaron a manos del gobierno (Trist, 1981) y se formó el Consejo Nacional del Carbón ${ }^{5}$. Preocupado por la baja productividad y la baja moral de los mineros, pidió al legendario Instituto Tavistock ${ }^{6}$ un estudio comparativo y longitudinal en el que aparecieran dos minas: una con alta productividad y alta moral, y otra con baja productividad y baja moral para encontrar diferencias significativas.

Tavistock estaba inmerso en dos proyectos: a) difusión de prácticas innovadoras de trabajo prometedoras de incrementar la productividad, y b) relaciones de grupo a nivel interfase (Trist, 1981). A la cabeza de estos proyectos se encontraba el sociólogo británico Eric Trist ${ }^{7}$ quien fue una pieza clave para el desarrollo de esta difusión. La mina de Highmoor había reportado que había un grupo de mineros que laboraba a estrato de pared corta y que practicaba un modo de trabajo muy peculiar y diferente a los sistemas tradicionales de burocracia y tecnocracia. El gerente de la mina era un hombre liberal y que cuestionaba el status de las cosas, por lo que había permitido que este grupo de mineros tuviese otro enfoque hacia su propio trabajo. Trist y otro sociólogo llamado Fred Emery ${ }^{8}$ pudieron entrevistar a los 25 mineros y sus hallazgos fueron sorprendentes. De las entrevistas derivaron varios principios de trabajo que se utilizarían en el desarrollo del concepto sociotécnico. Entre otros, los principios hablaban de grupos de trabajo que eran sistemas, del desarrollo de multihabilidades, de la discrecionalidad de los roles de trabajo, reglamentación interna del grupo,

incremento de la variedad en el trabajo para reducir el grado de burocracia. ${ }^{9}$ Un nuevo paradigma de trabajo había sido descubierto: aquellos que consideraban los requerimientos técnicos y sociales de una organización. El Consejo Nacional del Carbón escuchó lo que Tavistock tenía que decir en las personas de Trist y Emery, pero no estaba dispuesto a considerar otra 
alternativa que no fuese la de la burocracia tecnocrática. Esta era la elección prevaleciente. Las minas debían ser verticales y disciplinadas. Rígidas si se quiere.

La nueva alternativa se aproximaba al trabajo y al empleo con un solo enfoque total, no como entidades separadas. Es decir, las organizaciones existen para hacer trabajo, que involucran a la gente usando artefactos tecnológicos (duros o suaves), para llevar a cabo tareas relacionadas con los propósitos globales de la organización misma. Por tanto, las organizaciones, de acuerdo a Trist, deben ser visualizadas como sistemas sociotécnicos, más que un sistema social simple. Los sistemas social y técnico eran los factores substantivos (la gente y el equipo). El comportamiento económico y la satisfacción en el empleo eran los productos de estos factores. Su nivel cuantitativo estaba en función de la bondad del ensamblado entre ambos sistemas (Emery, 1978).

Para Eric Trist la idea de todo esto era muy clara: las bases para su concepción se las proveyó Lewis Mumford (1963), quien había sugerido que la antropología y la historia cultural estaban entrelazadas en una complicada red de causalidades mutuas; esto, a pesar de que el material y las culturas simbólicas de la sociedad no estuviesen conectadas por un principio simple de causalidad lineal, como algunos intérpretes de Marx han querido implicar (Trist, 1981). También aparece en Trist la idea de las opciones tecnológicas que hacen las sociedades como debidas a sus percepciones críticas del mundo. A medida que surgían y se desarrollaban nuevas tecnologías se abrían nuevas opciones para la sociedad. Ésta podía aceptarlas o no. La forma de elaboración de estas tecnologías podía ser destructiva o constructiva. Había consecuencias impredecibles. De hecho, después de la Segunda Guerra Mundial, las tecnologías de información provenientes de la segunda revolución industrial apenas estaban manifestando su potencial. Se aproximaba un gran cambio cultural similar al que produjeron las tecnologías de energía de la primera revolución industrial (Trist, 1981).

En los primeros años de la década de 1930, Eric Trist había estado involucrado en proyectos similares de ensamblado de sistemas sociales y técnicos en la industria del yute en Dundee, U. K. Usando entrevistas profundas, los trabajadores expresaban que igual podrían estar desempleados. Tal era el grado de alienación que imperaba en esta industria. Esto le dio la idea de que ambos sistemas interactuaban fuertemente. La Segunda Guerra Mundial mostró a Trist que un nuevo arreglo sociotécnico existía: las divisiones Panzer alemanas, formidablemente competentes para unir hombre y máquina y lograr su propósito de muerte. Es interesante notar que Francia, a pesar de los 
esfuerzos de De Gaulle, no había podido desarrollar algo similar.

A medida que avanzaba la guerra, otros sociólogos irrumpieron con hallazgos importantes para el mundo del trabajo y las organizaciones. Wilfred Bion (1946) había hecho experimentos con grupos sin líder, permitiendo al líder surgir espontáneamente en el grupo. Esto fue utilizado por los WOSB (War Office Selection Boards) para seleccionar oficiales más capaces de relaciones democráticas entre ellos y sus hombres (Bion, 1991). Otra influencia capital en los sistema abiertos de trabajo fue Kurt Lewin, quien había huido de Berlin a New Jersey escapando de los nazis, y en la Universidad de Princeton había fundado el Instituto Internacional de Relaciones Industriales, así como los NTL (National Training Laboratories). Lewin estaba empeñado en demostrar la superioridad del modo democrático dentro de los grupos al promover el compromiso para la acción de sus miembros. Ambos autores enfatizaron la capacidad del grupo pequeño para la autorregulación, un aspecto de la teoría de los sistemas cuya importancia seguía creciendo a medida que avanzaban las ciencias cibernéticas (Weiner, 1950). Es interesante señalar que el celebrado sociólogo americano Talcott Parsons ha hecho uso extensivo de estos hallazgos. Sobre todo cuando fundamentó una de sus obras clave: The Social System (1951).

\section{Democracia industrial}

La difusión de las bondades de los sistemas abiertos de trabajo (sistemas sociotécnicos) no fue tan expedita como se esperaba. Las bases de apoyo al cambio seguían limitadas, así como la permanencia en el poder de la burocracia y la tecnocracia.

Un proyecto de gran envergadura se dio en 1962 en Noruega, donde no se habían hecho grandes modernizaciones tecnológicas en comparación con otros países escandinavos. El crecimiento económico se había detenido; las grandes compañías de pulpa de papel estaban en bancarrota. Las firmas noruegas eran tomadas por las multinacionales. En muchos aspectos, este pequeño país comenzó a experimentar lo que Trist y Emery han llamado "turbulencia" (Trist, 1981). Noruega comenzó a perder lo que es más triste para un país: el control de su propio destino.

En el ala izquierda del movimiento sindical noruego se dio una súbita demanda hecha por los trabajadores de tener control sobre su propio destino. Ni los patrones ni los sindicatos entendían bien a bien de qué se trataba esto. Se instaló en la Universidad Técnica de Noruega un Instituto de Investigación Social para llevar a cabo una encuesta. Se nombró como director al sociólogo Einar Thorsrud ${ }^{10}$. Pero dadas las presiones políticas, Thorsrud creyó más conveniente que el proyecto fuera iniciado por un grupo externo. Eric Trist, nuevamente, condujo los momentos clave del proceso por 
parte del Instituto Tavistock. El equipo de planeación estuvo compuesto por Eric Trist, Fred Emery y Einar Thorsrud y los representantes de las dos confederaciones: la de sindicatos y la de empleadores. La tarea era producir un diseño y metodologías de investigación. Para ello involucraron a los accionistas de las empresas en cada etapa del proceso. La primera investigación estuvo encaminada a determinar el rol de los directores de los trabajadores, cuya existencia era obligatoria por ley, tanto en las empresas del Estado como en aquéllas donde el Estado tenía algún capital (dinero alemán entregado a Noruega por los aliados después de la guerra). Se entrevistaron a varios miembros de los cuadros de mando de las empresas, incluyendo a los directores de los trabajadores, los principales miembros de la administración y de la organización de sindicatos. Se encontró que, aunque los directores de los trabajadores tuvieran o no un desempeño sobresaliente, su presencia, aunque reforzadora del control democrático, no tenía efecto sobre los sentimientos de alienación en las naves de producción o sobre el desempeño (Trist, 1981). Se propuso entonces que, paralelamente, se asegurara la participación directa de los trabajadores en las decisiones en su propia área de trabajo. Estos hallazgos fueron ampliamente discutidos en las dos confederaciones y en los medios. Por consenso se decidió probar la toma de decisiones directa. Se seleccionaron dos sectores industriales para el experimento. Dos sectores que estaban bajos en productividad, pero que eran estratégicos para el futuro económico del país (papel, pulpa e industria metal-mecánica). Se discutieron los criterios sobre los cuales basar la selección de los experimentos sociotécnicos de campo y que deberían servir como proyectos de demostración. Los comités seleccionaron las plantas y fueron visitadas por parte del equipo de planeación para probar su adecuación al experimento y asegurar la participación local.

El equipo de investigación hizo un estudio de la cultura e historia noruega. Por ejemplo, la industrialización había sido tardía y más benigna que en otros países europeos y en Estados Unidos, donde la industrialización había ocurrido más temprano. Las relaciones industriales eran estables a nivel nacional donde ambas confederaciones habían aceptado que eran complementarias (Emery y Thorsrud, 1969). Noruega era un país que no había pasado etapas o que tuviera un patrón de rebelión a la autoridad. Tenía una tradición larga de igualdad mantenida a través de los años, más quizá que en otros países. Se formuló la hipótesis de que esta configuración era favorable para los objetivos del proyecto y la participación directa en el lugar de trabajo. Estas condiciones favorables fueron fortalecidas por la homogeneidad de la sociedad y por su tamaño pequeño. Los miembros de 
los diferentes grupos se conocían bien y se traslapaban. Si ellos decidían moverse en alguna dirección había redes de apoyo y soporte.

Sin embargo, la hipótesis de que la difusión del proyecto noruego ocurriría en lugares de trabajo de alto perfil no fue certera. Los lugares de trabajo quedaron encapsulados (Herbst, 1975). La difusión tendría lugar en otro sitio. Esto ocurrió en Suecia al final de la década debido al creciente interés que generó el experimento noruego en los trabajadores y las confederaciones de sindicatos. Thorsrud fue invitado a visitar el país. Para 1973 se tenían entre 500 y 1,000 proyectos de mejora en el trabajo. Éstos eran tan variados en forma, tamaño, sector industrial y objetivos como lo permitían las diferentes industrias. Una nueva generación de suecos (mejor educada y más afluente) rehusó (por ausentismo y rotación) hacer los trabajos más opacos y serviles. Pero la importación de europeos del sur creó problemas sociales. Se tenía que hacer algo. Los gerentes y los sindicatos retomaron el enfoque noruego y lo adaptaron a sus propios propósitos.

\section{Calidad de vida de trabajo}

Este retomar el enfoque noruego por parte de los países del norte de Europa para paliar los conflictos generados por la alta inmigración española, portuguesa y norafricana produjo cambios que mejoraron la calidad de vida de trabajo de los obreros, azafatas, mucamas, estibadores, sirvientas y trabajadores (as) en general. Esto sucedía en la década de 1970. El fenómeno de la emigración española y portuguesa es harto conocido. Sabemos que ambos países estaban bajo dictaduras extremas y obligaba al exilio voluntario a cientos de miles de sus habitantes. El empleo en esos países era precario.

Pero, se estaba alcanzando un nuevo estado de bienestar, similar a aquel que había generado el fordismo, el taylorismo y las empresas alineadas con Keynes. Los países escandinavos constituyeron un eje para hacer frente y absorber mejor la inmigración extranjera, y para llevar a cabo los postulados y las derivaciones del proyecto noruego, que para entonces se había extendido a Suecia y Dinamarca. El estado de bienestar contemplaba al empleo y sus dimensiones como algo fundamental para insertar el concepto de calidad de vida de trabajo. Este concepto era el consenso logrado en un simposio internacional que se había dado en Arden House de Columbia University. El término QWL (Quality of Working Life) ${ }^{11}$ fue uno de los productos resultantes de dicho simposio pues ha servido, de alguna o varias formas, para definir un cierto estado de bienestar. Los países escandinavos acordaron una serie de modificaciones que condujeron a nuevas leyes laborales. Las nuevas generaciones de escandinavos, como señalábamos más arriba, pidieron y consiguieron tener en sus empleos aspectos 
relacionados con la reducción de la alienación: Eric Trist los ha clasificado como propiedades:

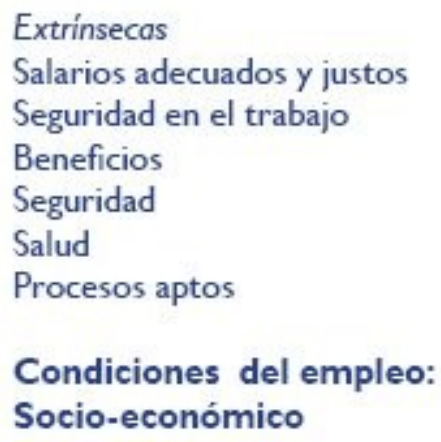

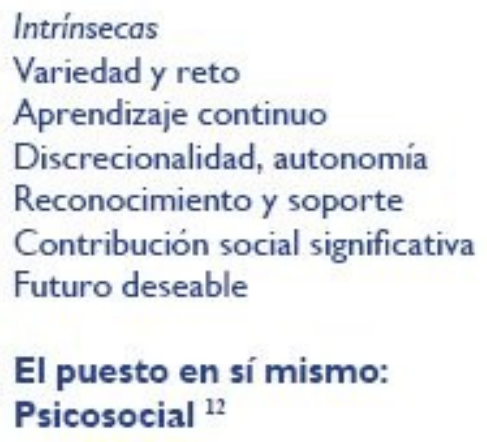

Este estado de bienestar alcanzó niveles espectaculares en 1975, cuando la compañía automotriz sueca Volvo implementó un arreglo sociotécnico en su planta de Kälmar. 1975 fue un año de pérdidas millonarias para la industria automotriz, sobre todo para los grandes líderes como Ford y GM, que habían tenido que reducir su plantilla de personal y abatir costes de producción. Volvo, con la mitad de empleados trabajando en forma de equipos autodirigidos y con énfasis en cogestión y cooptación ${ }^{13}$, obtuvo resultados impresionantes en materia de rentabilidad, rendimientos para los accionistas y satisfacción del personal. Hoy en día, GM y Ford continúan enfrentando problemas de productividad, dados los problemas sociales generados por la migración en sus plantas del mundo. En Bélgica, cuando estuvo a punto de cerrar una de sus plantas, Ford se enfrentó a una protesta de 1,500 empleados que perdían sus puestos de trabajo.

El estado de bienestar se incrementó cuando varios países europeos implementaron la cooptación como método de negociación. A continuación aparece una distribución de las formas de democracia industrial (Trist, 1981) en los años 80 (década que corresponde a un quinto ciclo Kondratieff ). ${ }^{14}$ 


\section{Escala: 0 - 4}

\begin{tabular}{|c|c|c|c|c|}
\hline & $\begin{array}{l}\text { Negociación } \\
\text { colectiva }\end{array}$ & Representatividad & Patrón & $\begin{array}{c}\text { Referida al } \\
\text { trabajo }\end{array}$ \\
\hline Noruega & 4 & 3 & 1 & 2 \\
\hline Suecia & 4 & $3^{-}$ & $1^{-}$ & $2 \overline{1} / 2$ \\
\hline Paises Bajos & 3 & $2^{-}$ & $1^{-}$ & 1 \\
\hline Australia & 2 & I & 1 & 1 \\
\hline Alemania & $2_{-}^{-}$ & 4 & -1 & -1 \\
\hline Francia & $2_{-}^{-}$ & I & -1 & -1 \\
\hline Gran Bretaña & $4^{-}$ & 0 & I & $0+$ \\
\hline USA & 2 & $0+$ & I & 1 \\
\hline Canadá & 2 & $0+$ & $I_{-}$ & -1 \\
\hline Yugoslavia & $0^{-}$ & 4 & $4^{-}$ & $0+()$ \\
\hline
\end{tabular}

\section{Intrusión de la globalización}

La década de 1980 marcó derroteros hacia nuevos consensos y estados de bienestar. La situación comenzaba a cambiar. El empleo ya no era seguro. Aparecían signos de advertencia en Europa y en Estados Unidos en cuanto a la migración que aumentaba día a día. Los españoles que habían escapado del desempleo marchando al norte en busca de trabajo, la mayoría de las veces poco significativo, regresaban a España donde el dictador Franco había muerto en 1975. Esto creó un problema para el nuevo gobierno de la monarquía. Surgieron figuras señeras como Adolfo Suárez, que fue el arquitecto de la transición española. Pero la década fue problemática. El país no estaba preparado para semejante oleada de nacionales. No había trabajo. Marruecos estaba despidiendo a los suyos que se refugiaban en España. Francia era el destino favorito, por supuesto, de los argelinos y otros países de África. Londres, con su gran población de indios, musulmanes, chinos y africanos era una metrópoli todavía más cosmopolita, sofisticada, cara y perversa con los desposeídos. Bélgica, Alemania e Italia enfrentaban problemas semejantes.

Las globalizaciones de la tecnología habían comenzado cuando Nixon abrió las fronteras comerciales y el mutismo de China. Se comenzaron a seleccionar países de Centroamérica para hacer la maquila por sueldos miserables. La producción pesada se trasladó a esos países. La cibernética avanzaba y con ello privilegiaba a los que tenían acceso a las tecnologías de información. Comenzó el rápido boom de las tarjetas de crédito; la revolución del microprocesador de Motorola hizo su aparición. Además de la tecnología, se estaban globalizando los empleos, la cultura, las formas de comunicación, los estilos de vida, el hábitat. 
Ello trajo consigo severas disfunciones, pero también fue muy revelador constatar que las globalizaciones son las grandes patrocinadoras de las diferencias antropológicas cuando pensamos al otro (Reguillo, 2002). También resulta paradójico que a mayor tecnología exista mayor precarización del trabajo. Dicha ausencia es para los más descastados (Cfr. violencia actual en Francia). La inseguridad laboral está afectando ya a las capas medias de la sociedad. Antes era una fortaleza tener sociedades con pleno empleo, pero ha hecho ya irrupción lo precario, lo discontinuo, lo impreciso y lo informal, y parece que este modo de vida en los países del sur se está extendiendo a los centros neurálgicos del mundo occidental. Otra realidad parece ser que los países que han quedado excluidos de las redes de la información los hace prescindibles (Castells, 1999). La sociología no tiene respuestas hoy en día para comprender este conjunto de fenómenos nuevos que ha traído consigo la globalización (Ortiz, 1998). La individualidad pareciera perderse en la globalización de la cultura (Reguillo, 2002). Hay una relación inversamente proporcional entre la prosperidad del capitalismo y la degradación de la sociedad. Jeremy Rifkin (1997) señala que el desempleo se incrementará a medida que avance la tecnología basada en las comunicaciones. Esto eliminará millones de empleos en los sectores agrícolas y de servicios.

\section{¿La alienación laboral tiene remedio?}

Tal parece que los sistemas sociotécnicos han recorrido un largo camino desde sus lejanos orígenes. Ha sido nuestro pretexto para una reflexión sobre el devenir (sustantivo) de la sociedad. Los sistemas de trabajo están ahí, y seguramente seguirán ahí, pero nosotros mutamos. Nuestro estilo de vida, nuestro hábitat, nuestra forma de comunicación, nuestros valores, nuestras estructuras cognitivas, están siendo alterados profundamente por la tecnología, una tecnología demoledora e inmisericorde. Nos pensamos en función de ella. El itinerario que hemos tratado de mostrar en el tiempo y en el espacio nos dice que .los ciclos de la vida, la labor, la acción, la ciudad, el mercado, son caprichosos y efímeros. Nuevas corrientes nacen profetizando que llegaron para quedarse. Poco después caen. Una nueva teoría, un nuevo enfoque, un nuevo método hacen su aparición. Muchos se adhieren a ellos, se forman bandos encontrados, se discuten en congresos y simposia, se trata de ordenar al mundo bajo nuevas reglas, se trata de un juego de poder. Dice Bourdieu (1999) que el poder está presente en el campo científico, ¿y dónde no?, ¿De quién es el mundo sino de los poderosos, de los que dictan la moda, tanto en la ciencia como en el arte? De repente irrumpe un profeta que dice que hay que darle otra oportunidad a la socialdemocracia, que hay que volver a los consensos del bienestar de 
antaño. Su pensamiento es fortalecido por líderes políticos de países poderosos. Se declara lejano al sistema dominante, sin embargo es un reforzador del mismo. Surge otro más que afirma que la emergencia de las globalizaciones y de un mundo en constante movimiento requiere de un nuevo sistema de comunicación, nuevas formas de sintaxis y lenguajes más activos. El carácter se corroe al enfrentarnos a una realidad que ofende: empleos contingentes, trabajo precario, flexibilidades en los salarios, realidades de hoy. Consumimos la polis, asesinamos a la realidad. La realidad está siendo objeto de maltratos por la sociedad de consumo. La comunicación fue uno de los aspectos característicos del siglo veinte, pero hoy es pivotal para una reflexión serena sobre democracia, amor y tiempos cambiantes (Peters, 1999). Pero llegará el día en que personas con diferentes biografías examinen los problemas sociales habiendo alcanzado con ello la internacionalización de la ciencia social.

Quisiera incluir aquí un fragmento del discurso que Louis Davis pronunció al aceptar la presidencia, en 1978, del Instituto Internacional de Calidad de Vida de Trabajo, con sede en Paris:

Calidad de vida de trabajo abre una serie de preguntas básicas, se involucran serias cuestiones de valores, de propósitos organizacionales y del tipo de sociedad que uno quisiera en el futuro. Si deseamos un mundo más humano y más democrático, debemos pensar en el trabajo, no sólo como el modus vivendi, sino también como un vehículo para la dignidad humana.

Las sociedades más avanzadas no pueden permanecer estáticas en sus modalidades prevalecientes sin producir una disfunción severa y un sufrimiento inaceptable.

Incrementar la calidad de la vida en el lugar de trabajo es una de las cuestiones centrales de nuestro tiempo. Los esfuerzos requeridos, la determinación necesaria para sostener los programas a pesar de la resistencia y retrocesos serán de gran valor. (Louis Davis, 1980)

¿Llegará otra bonanza para la humanidad? No lo sé. Nada en este mundo puede quedar resuelto para siempre. Ningún triunfo determina el porvenir. Ningún tratado fija por mucho tiempo las fronteras entre dos países. Ninguna revolución asegura una sociedad eternamente dichosa. Estoy ansioso por saber qué habrá creado mi generación al final de este ciclo.

\section{NOTAS}

${ }^{1}$ Cuando la obra "La cantante calva" de Eugene lonesco fue puesta en escena en mayo de 1950 en Los Noctámbulos de Paris, despertó murmullos de descontento, indignaciones espontáneas y burlas. Jacques Lemarchand, 
que ha sido un crítico teatral irreverente, implacable y sagaz a través ahora de muchas décadas, reseñó tal noche de estreno. Con su técnica de lanzar varios Bravo!, Bravo! al final de la obra y entrar a contrapelo, como un salmón, desde la salida del teatro, de nuevo por entre el flujo de los airados teatrófilos, para escuchar sus quejas, lamentaciones, las expresiones de agravio y las agudezas aceradas que un espectáculo que les ha desagradado inspira a los notables. Más de veinte veces escuchó "pero, en fin, ¿por qué La cantante calva? Me parece que no ha aparecido en escena cantante alguna. Por lo menos yo no la he visto. ¡Y calva!..." "Ha visto usted que alguno de los personajes fuese calvo"... "¿y ese bombero? ¿Qué tiene que hacer ahí un bombero? ¿De quien se burlan?” Era evidente que los notables no habían comprendido; les prometían una cantante calva, se sentían robados, lo que no perdonan.

El teatro de ionesco no es un teatro psicológico, no es un teatro simbolista, no es un teatro social, ni poético, ni superrealista. Es el más extraño y espontáneo de la postguerra. Es un teatro de aventura, tan irracional que viola constantemente las reglas del juego. Así es el tema que me propongo abordar, la alienación laboral es irracional, no es simbolista, no es poética, no hace alusión a su título. El misterio de la voz búlgara es un nombre que se me ocurrió después de serias consideraciones a-la-ionesco. No hay voz ni hay Bulgaria en el tema, no hay misterio, pero hay las tres cosas.

${ }^{2}$ La globalización laboral está en el debate, pues la rotación de puestos internacionalmente hablando son sólo para las élites, no para los que están sumidos en la precarización.

${ }^{3}$ Louis Davis (1925-2000), fue el creador del curso "Designing Sociotechnical Organisations" para la UCLA. Davis armó este curso con la participación de Eric Trist (de quien hablaré más adelante). El curso forma parte ahora de la curricula de la Maestría en Diseño Sociotécnico de la misma universidad. Davis también propuso el término calidad de vida de trabajo en 1973 para definir el concepto y la filosofía detrás de los sistemas abiertos de trabajo.

${ }^{4}$ Nombre que se le da también a los sistemas sociotécnicos, de acuerdo a Ludwig von Bertalanffy

${ }^{5}$ El NCC (National Coal Council) fue un organismo señero en materia del cambio planeado en los enfoques hacia las organizaciones.

${ }^{6}$ El Instituto Tavistock de Londres fue fundado con dos objetivos: la clínica Tavistock, por donde han pasado los grandes estudiosos de la conducta humana, desde Freud hasta Eriksson, pasando por Fromm y Jung, y el Instituto Tavistock propiamente dicho, orientado al estudio de grupos de trabajo y a encontrar la interfase entre el obrero y el patrón. Hoy en día, Tavistock es una leyenda y una referencia obligada para los estudiosos y 
escolares que quieran empaparse de los más grandes hallazgos y desarrollos en materia de sociología y psicología. Su acervo documental del siglo diecinueve es uno de los más grandes del mundo. Se crearon, incluso, los talleres y seminarios Tavistock a través de los NTL (National Training Laboratories).

${ }^{7}$ Eric Trist es considerado como uno de los padres fundadores de los modernos sistemas de trabajo, basados en los postulados de von Bertalanffy.

${ }^{8}$ Fred Emery había sido minero en su juventud y había estudiado ciencias sociales. Su participación en este proyecto fue fundamental.

${ }^{9}$ Tavistock Institute (1968) Estos principios fueron documentados en un texto ya clásico: Jacques, pérdida, redescubrimiento y transformación de una antigua tradición de trabajo, en Ontario Papers on Quality of Working Life ${ }^{10}$ Einar Thorsrud fue una pieza clave para el desarrollo del proyecto. Años después documentó el trabajo hecho por Tavistock en Noruega en su texto Una estrategia para desarrollo y cambio social en la industria: reporte sobre el proyecto de democracia industrial en Noruega.

${ }^{11}$ En 1972 Louis Davis, otro padre fundador de los sistemas sociotécnicos, propuso el término calidad de vida de trabajo para establecer el concepto detrás de ellos. Esta propuesta fue aceptada por unanimidad. El término QWL (quality of working life) se usa hoy en día para designar un estado de bienestar de individuos y comunidades. Se aplica, tanto a la vida urbana, cuanto a la vida laboral, y está definida por muchos factores, algunos subjetivos y otros "duros".

${ }^{12}$ Fuente: Distribution of forms of industrial democracy in selected countries, en "The Evolution of Sociotechnical Systems" (Trist, Eric and Thorsrud, Einar, eds). Ontario Papers on QWL, 1984.

${ }^{13}$ La cogestión fue un arreglo muy popular en los países del Este de Europa cuando existía la Cortina de Hierro del bloque socialista. Países como Hungría, Yugoslavia y Rumania intentaron colocar a los obreros dentro de la administración de las fábricas sin resultados. La cooptación ofreció resultados sólidos en materia de negociación y selección autónoma.

${ }^{14}$ El economista soviético Nikolai D. Kondratieff creó su ciclo económico en los años 20. Sin embargo no tuvo difusión y aceptación hasta los 40 cuando fue traducido al alemán. Tuvo una ola expansiva hasta los 70 , cuando se extinguió. Hoy ha tenido un resurgimiento notable. Kondratieff establece que la economía mundial pasa por ciclos. Cada cierto número de años se repite la "ola" Kondratieff. Esto ha sucedido desde 1819, pasando por 1896 (precios de ganga en Estados Unidos), 1929 (la gran depresión), hasta nuestros días. Esto se repite cada 54 años. 
15 Trist, Eric (1982). The Evolution of Sociotechnical Systems, in Ontario Papers on QWL. The Ontario Press: Canada.

\section{FUENTES DE CONSULTA}

ALEXANDER, Michael A. (2002). "The Kondratieff Economic Cycle"iUniverse.com. March.

Arendt, Hannah (1958). The Human Condition. Chicago: University of Chicago Press.

Baudrillard, Jean (2003). La société de consommation. Saint-Amand (Cher): Denoël.

Beck, Ulrich (2000). Un nuevo mundo feliz. Paidós. Barcelona.

Bendix, Reinhard (1962). Max Weber: An Intellectual Portrait. Garden City, NY.

Bertalanffy, Ludwig von (1956). General Systems Theory. General Systems Manual 1:1-10.

Beveridge, William (1975). The Economic Plateau. University of Pennsylvania Press: Penn State.

Bion, W. R. (1946) "The leaderless group project". Bulletin of the Menninger Clinic, 10.

. "Experiences in groups V". Human Relations, 3:3-14.

Bridges, William (1993). Surviving corporate transition. Doubleday. New York. Bourdieu, Pierre (1999). La miseria del mundo. Akal. Madrid.

Castells, Manuel (1999). La era de la información: economía, sociedad y cultura. Siglo xxi. México.

Chiapello, Eve and Boltanski, Luc (2000). El nuevo espíritu del capitalismo. Akal. Barcelona.

Camus, Albert (1965). Quotes. Harvard University Press: new York.

Davis, Louis (1980). Quality of Working Life. University of California in Los Angeles Press. Los Angeles.

(1981). Design of Jobs. UCLA Press. Los Angeles.

(1957).“Job design research". Journal of Industrial Engineering. Nov-Dec

Doss, Richard (1990). Theory P. Doubleday. Los Angeles.

Emery, Fred and Thorsrud, Einar (1969). Form and content in industrial democracy. Oslo University Press. Oslo. Tavistock.

Emery, Fred (1978). The emergence of a new paradigm of work. Canberra: Centre for continuing Education. A. N. U.

García Canclini, Néstor (1999). La globalización inaugurada. Paidós. Buenos Aires.

Giddens, Anthony (1998). La tercera vía. Taurus. Madrid.

lanni, Octavio (1997). Teorías de la globalización. Siglo xxi. México.

Keynes, John Maynard (1927). Las consecuencias económicas de la paz. 
Hamish Hamilton. London.

Lacqueur, Walter (1988). The dream that failed: reflections on the Soviet Union. McGraw Hill. New York.

(1990). Fascism: Past, present, future. McGraw Hill. New York .

Lewin, Kurt (1951). Field theory in social science. Harper and Row. New York.

Marx, Karl (1959) El Capital. Crítica de la economía política. México: Fondo de Cultura Económica.

McGilligan, Patrick (1997). Fritz Lang: the nature of the beast. St. Martin's Press. New York.

McGregor, Douglas (1985). The human side of enterprise. John Wiley. New York.

McLuhan, Marshall (1964). Understanding media. McGraw Hill. New York. Mead, Margaret (1967). Adolescencia y cultura en Samoa. Knopf. New York Miller, Lawrence (1997). Whole systems architecture. Miller Press. Atlanta. Mumford, Lewis (1963). Technics and Civilization. Harcourt, Brace and World: New York

Ortiz, Renato (1998). Los artífices de una cultura mundializada. Siglo del hombre. Bogotá.

Parsons Talcott (1968). "The Social System”. SILLS et al (Eds.): New York. Reguillo, Rossana. (2002): "Políticas de representación. Poder y antropología de la comunicación". Anuario de Investigación de la Comunicación IX, México: CONNEICC, pp $37-54$.

Rempel, Gerhard (2000). Lectures. Western New England College.

Rifkin, Jeremy (1997). The end of the job. Doubleday. New York.

Sennett, Richard (1998). La corrosión del carácter. Anagrama. Barcelona.

Singer, E. A. (1959). Experience and reflection. University of Pennsylvania Press. Philadelphia.

Sussman, Gerhard (1976). Autonomy at work. Praeger. New York

Taylor, Frederick (1993). Principios de la administración científica. Herrero Hermanos Pubs: México.

Thorsrud, Einar (1985). "Una estrategia para el desarrollo y cambio social en la industria: reporte sobre el proyecto de democracia industrial en Noruega". Cuadernos del Ontario Quality of Working Life Centre. Toronto.

Trist, Eric (1981). The evolution of sociotechnical systems. Ontario Ministry of Labour. John Wiley. Toronto.

Watson, Peter (2002). Historia intelectual del siglo xx. Crítica. Barcelona.

Weber, Max (1947). Essays on Sociology. New Horizons: New York

(1978). Economía y Sociedad. México : Fondo de Cultura Económica. « Conceptos sociológicos fundamentales » 
(1999). Ética protestante y espíritu del capitalismo. FCE: México.

Wittgenstein, Ludwig (1956). Tractacus Logico-Philosophicus. Hamish Hamilton. London. 